\title{
Mapping the Monetization Challenge of Gaming in Various Domains
}

\author{
Evangelos Markopoulos ${ }^{1}$, Panagiotis Markopoulos ${ }^{2}$, Mika Liumila ${ }^{3}$, \\ Younus Almufti ${ }^{1}$, Vasu Aggarwal ${ }^{1}$ \\ ${ }^{1}$ HULT International Business School, 35 Commercial Road, Whitechapel, E1 \\ 1LD London United Kingdom. \\ ${ }^{2}$ University of the Arts London, Elephant and Castle, SE1 6SB, London, \\ United Kingdom. \\ ${ }^{3}$ Turku University of Applied Science, Joukahaisenkatu 3, 20520, Turku, \\ Finnland. \\ evangelos.markopoulos@faculty.hult.edu,p.markopoulos1@arts.ac.uk, \\ mika.luimula@turkuamk.fi yalmufti2015@student.hult.edu, \\ vaggarwa12016@student.hult.edu
}

\begin{abstract}
The cost of developing successful games for either entertainment or business purposes is a high-risk investment but mandatory due to the nature of the sector. However, there are discrete and innovative ways that minimize the investments risk and assure profitability without losing the player's engagement. Gaming monetization can be approached from direct or indirect financial charges based on the scope of the game and its target group. As of today, no monetization practice can be considered as a silver bullet as they are all affected by geographical, cultural, social, economic and other factors. This paper attempts to define the major monetization elements in the gaming industry. It also attempts to define the major gaming categories and subcategories and associate on them the monetization elements and techniques. Furthermore, it creates a map for the development of gamification monetization approaches per case which can contribute towards effective gaming investments management.
\end{abstract}

Keywords: Gaming · Gamification · Serious Games · Investment Management - Entertainment Games · Monetization · Ethics · Management

\section{$1 \quad$ Introduction}

The growth of the computer and digital games industry has turned out to be nonpredictable in market size and number of applications. At the same time the discipline of games design and games development entered unmapped technoeconomic areas where challenges and threats are can be as surprising as the opportunities. The wide range of games (serious entertainment, simulations, etc) and the limited lifespan they have in terms of player engagement turns the development of computer games into high-risk but also high-value investments. 
Games development turned out to be complex technological projects and initiatives that create masses of users, require serious investments, utilize tremendous computing resources, and demand continuous design and artistic perfection in order to remain engaging. The cost of developing successful games for either entertainment or business applications is a high-risk investment but mandatory as well due to the nature of the sector. However, there are discrete and innovative techniques and practices to minimize such investment risk and increase profitability.

Game monetization practices is a field in gaming economics that grows faster than the games themselves. In entertainment games, monetization can be approached with direct or indirect financial charges while on serious games monetization is measured by the contribution of the game to effectiveness of the organization, the performance of the employers, their training effectiveness and their overall positive contribution to the operations of the organization.

Applying monetization techniques in any type of game involves socioeconomic and psycho-economic elements as well. The psychology of the gamer plays a significant role on the adaptation of a monetization technique. It must also be noted that monetization the outside entertainment games environment must take into consideration legal dimensions as well. When designing monetization models for serious games, parameters such as labour rights, data protection rights, confidentiality performances scores, etc., must be considered as well.

This paper attempts to define the major monetization elements in the gaming industry. It also attempts to define the major gaming categories and subcategories and associate on them the monetization elements and techniques and create a map for the development of gamification monetization approaches per case that can contribute towards effective gaming investments management.

\section{The Gaming Industry Economics, and the Rise of the U.K.}

The last 40 years games have tremendously changed due to the massive technological advancements on the information technology sector and the rapid commercialization of computers. Computer games play today a significant role in the life of people regardless their age, sex or social or financial status. This phenomenon has been analyzed over extensive research indicating the impact games have in modern society [1]. Nearly $77 \%$ of the families in the United States own videogames, and nearly $46.6 \%$ of the employees in Germany play games during working hours.

The computer games industry grows with exponential rates. The industry in the United States had a value of 16.9 billion USD in 2016 and 17.6 billion in 2017 with 4.7 billion to be from consumers spending. The industry is expected to reach the value of 20.3 billion by 2020 in the US with the action shooting games to be the most popular.

An impressive increase is also recorded on the gamers as well. In 2016 there were 200 million gamers in North America and 912 million in Asia Pacific. Gender does not seem to differentiate games. Women are quite active in games with significant presence in some (69\% play match 3 genre) and less presence in others (6\% in racing games).

The is tremendous growth of the markets created new business success stories. On 2017, the Chinese entertainment company Tencent generated revenues of 18.1 billion U.S. dollars. [2] 
Impressive development is also indicated in the UK gaming industry as well. The gamers in the UK in 2017 were 32.4 million making the 5th largest video game market, (China, USA, Japan and Germany were the top four). Consumer spending increase in the UK as well, reaching $£ 4.33$ in 2016 and $£ 5.11$ in 2017 . This growth is reflected in the growth of the computer game companies in the country. On 2018, 2,261 active games companies were recorded in the UK, developing all types of games from mobile, $\mathrm{PC}$ and console, to VR/AR, esports and Artificial Intelligence. [3]

\section{Game Categories and Design Elements.}

Various disciplines in the gamification industry are differentiated in terms of their applications and the type of users they have. However, an overlap exists in the combination of competitive and design elements with the motive of increasing user engagement and support learning [4], [5].

Primarily games can be categorized into entertainment and serious/business games. The entertainment games include, Massively Multiplayer Online games (MMO), simulations, role playing (RPG), first \& third person shooters (FPS/TPS) which have been spread across various genres like puzzle, strategy, action and racing. This gamified approach includes various design elements created for pleasure and entertainment with minimalistic support and existence of predetermined learning outcomes.

Serious Games, on the other hand, is an upcoming trend with significant potential to revolutionize business management and operations. Serious games, are games carrying game-inspired design elements, designed not for entertainment but gamified structurally to either gamify a corporate's content (Structural Gamification) or turn the content into a game (Content Gamification) with a predetermined objective [5].

A serious game, comprised of several design elements (points, adaptation to difficulty and a narrative) can be similar across other serious game s [6].

Under a structural gamification approach, in serious games, the corporate content is transformed into a template - based approach with plug-and-play functionality within the game and minimalistic structural changes to the native content. This can be achieved by using design elements to a design structure of a game that applies to different corporate contents. Content Gamification on the other hand involves a one-time unique structure created for specific corporate content, incorporating various design elements, unique to the content type. For example, business simulations (or 'gamesims') [7] for inventory management training the Purchase Department would constitute gamifying the inventory management content.

In between the entertainment and cooperate games a new category exists which emphasizes on the learning experience of any game. The educational games are based on gaming mechanics which increase the ability to learn new skills [8]. Today gamification has applications in the educational sector, which can potentially disrupt the dynamics of education due to lack of active engagement and motivation amongst students of any age and type, in cognitive learning processes [5]. Educational games can incorporate competitive design elements with motives for fulfilling the market gap of lack of engagement. Research indicates that gamification in education including science, mathematics, cultural heritage, foreign languages, health, computer science, software engineering, business and logistics [9]. 
Improving upon the antecedents of the user engagement such as the player's cognitive abilities on task management, sense of control would lead to the user incrementally improving the in-game performance on the outcomes of education [10] and the predetermined objectives [11].

\section{$4 \quad$ Monetization Practices.}

The gaming industry evolution can be characterized by innovation which in most cases require high budget with uncertain success. Game monetization refers to the strategy and practices that assure return on investment in game development projects and initiatives.

In monetization, there are fundamental revenue-generation approaches that can be interlinked. One of them is the utilization of the advertising space. This tackles the way a firm can utilize web spaces to sponsor advertisements that can generate revenue. This kind of classic approach has been adopted by many industries with online presence. Subscription is considered to be another base of revenue generation and it can manifest itself in seven different ways based on the involvement of the user, the duration and other options. The decision on which subscription a user should select is highly depended on the needs of the user. Various types of subscriptions can be used together; this is widely used in mobile applications such as Headspace.

Monetization practices and strategies can also be developed around the utilization of the game's data. Data driven monetization refers to the use, selling or access of important data to generate revenue. This is one of the main monetization models used in websites such as Facebook that allows data access to other firms [12].

While the data-oriented monetization utilizes the information of users the agencyoriented monetization focuses on access to the platform and increase its popularity in various marketplaces. Ebay is such an example which allows access only through a commission.

More monetization practices and approaches are the agent oriented and lifestyle-oriented ones. The Agency-based monetization is usually interlinked with subscription and has been used effectively in human resources management and recruiting firms [10]. The Lifestyle based monetization is not commonly used in gamified products as it usually refers to the selling of merchandise or direct to consumer-based models.

However indirect marketing can be achieved in gamification through which lifestyle products can be promoted as part of the game scenario. Table 1 presents these five monetization orientations that can be utilized by a game from many dimensions such as before, during and after game-play.

Table 1. Categorization of monetization practices.

\begin{tabular}{ll}
\hline Monetization Base & Example \\
\hline Ad Space & Banner Ads \\
& Affiliate Marketing \\
& Native Advertising \\
& Branded Content \\
& Ad Free
\end{tabular}




\begin{tabular}{ll} 
Data Base & DaaS (data as a service) \\
& Packed Data \\
& DIY DaaS \\
& Optimization \\
Subscription Base & Virtual Goods (microtransactions) \\
& Free DIY or Paid DFY \\
& Pay What You Want \\
& Pay Per Device, License, User \\
& Freemium \\
Agency Base & Commission \\
& Subscription Fee \\
& Pay to: Offer, List, Get Noticed, \\
& Cashback \\
& Direct to Consumer \\
& Branded Merchandise \\
\hline
\end{tabular}

\section{$5 \quad$ Mapping the Monetization Practices to Game Domains.}

The monetization practices in the context of the different game categories have also different applications that can be either used as standalone practices or in various combinations towards achieving unique pathways for revenue generation and profitability.

In serious games two subscription-based monetization approaches can be used effectively. The first one is the freemium business model that can be used primarily on the structural gamification applications. The term is composed from the words "free" and "premium" indicating that a service is offered for free on the basic operations, but for premium add-on services, functionalities or related services, a fee is charged [13].

Through the application of a freemium price model, serious games can monetize various design elements that can provide basic operations such as employee training and productivity enhancement. However, combinations of other operations and functionality can be sold in form of a premium 'add on' allowing serious games to be agile in use and cost, and therefore more applicable in different corporate departments. For companies like 'Tencent' who invested in the freemium business model and generated revenues over $\$ 18.1$ billion in 2017 [14], monetization through the freemium model turned out to be very attractive.

The second subscription base that can be used is 'Pay Per User', which works in team-oriented products and services. Depending on the organisational size, the potential for monetization exists where large number of employees need to be involved. Therefore, implementation and adaptation of a 'Pay Per User' coupled with a freemium subscription base would allow sustainable and affordable monetization opportunities.

These monetization practices can also be adapted in the entertainment games domain which currently benefits from virtual goods with various microtransactions on free games. A successful example is Fortnite, which generated revenues of $\$ 318$ million in May 2018 [15]. The specific approach allows users to get premium add-ons such as various game-skins and Experience Point (XP) boosts. These features, however, don't give a competitive advantage but support a lower user churn rate and product loyalty. 
Education games on the other hand could benefit significantly from the 'Pay Per Device' subscription approach which allows education institutions to be charged a fee for each student who participates in the game. This subscription base could work well on a tier-based system, according to the size of the education institution. Another potential subscription base would be 'Pay Per License' where institutions would pay to be receiving each gamified solution being offered by the provider.

\section{$6 \quad$ Niche Markets and Monetization Approaches.}

The evolution of gamification and the monetization practices are aligned with the evolution of the technology and the areas of applications games can contribute. The rapid development of the gaming industry does not allow monetization models to be settled down in the PC, console and mobile gaming regardless the type of game (serious, entertainment, educational). This has caused challenges for startups who enter in gaming business with new ideas. Reaching the visibility needed in heavily competed market places is very demanding, thus the probability for success can be significantly lower.

New market places are being born and dying every now and then even in the gaming industry. A new promising market is the Virtual Reality games where monetization faces various challenges primarily due to the cost of VR game operations. Early adopters in VR have not yet been as successful as technology providers have been expected. Even the new technologies have the same type of challenges Microsoft Kinect motion detection sensor have had earlier. Both VR glasses and Kinect sensors have been designed for consumer markets.

However, monetization models in non-consumer markets are totally different, making traditional game companies face difficulties on apply other monetization models. The prime reason for these difficulties is because they try to utilize game technologies by being focused on projects rather than service innovations. Figure 1 presents an example of monetization model for exergaming [16].

Digital rehabilitation markets are fragmented with thousands of single solutions. This led to the established of the DigiRehab consortium which unites the Finnish digital rehabilitation industry into open business ecosystems. This monetization practice relies on joint digital physical therapy and gamified solutions for exercise, award, IoT, user profile, and analytics management provided by various companies in a business ecosystem. Currently, research is been executed in prevention and rehabilitation. 


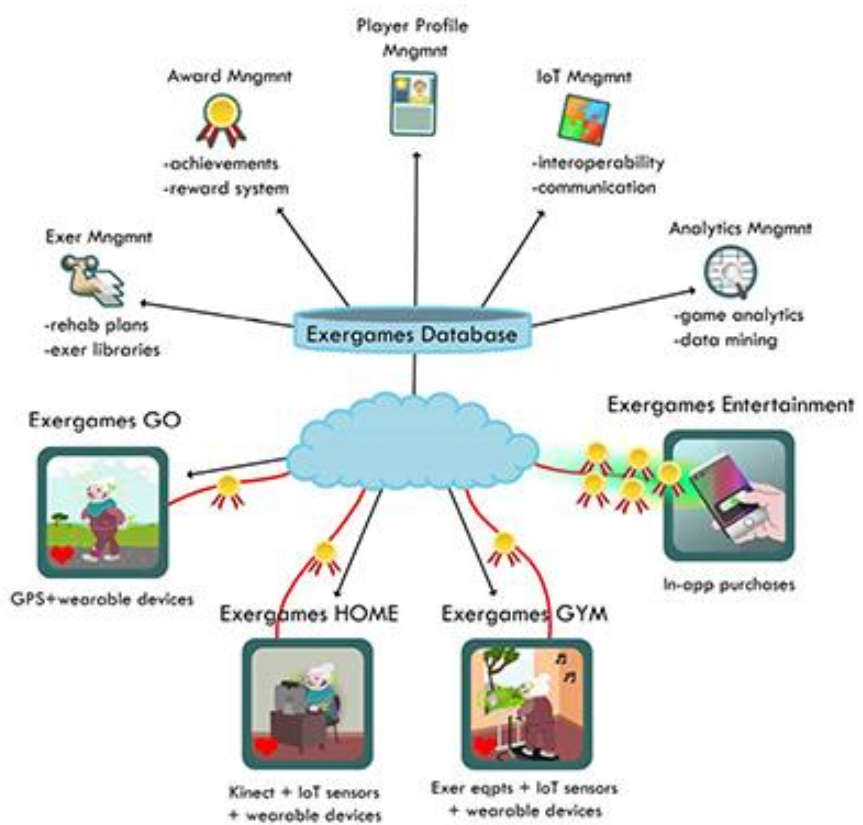

Fig. 1. Monetization model in digital physical therapy and gamified solutions for exercise.

This monetization model can be scaled from the healthcare sector to the technology industry. It has been experienced that safety training solutions for example in VR, require various expertise areas such as exercise (including health, safety, environment, and quality), pedagogy, player profile, natural language understanding, and analytics management.

To manage such challenges, strategic multi-disciplinary partnerships need to be created like the Finnish National Safety Training Consortium which has been established by the Turku University of Applied Sciences and participated in various applications (Fig. 2).
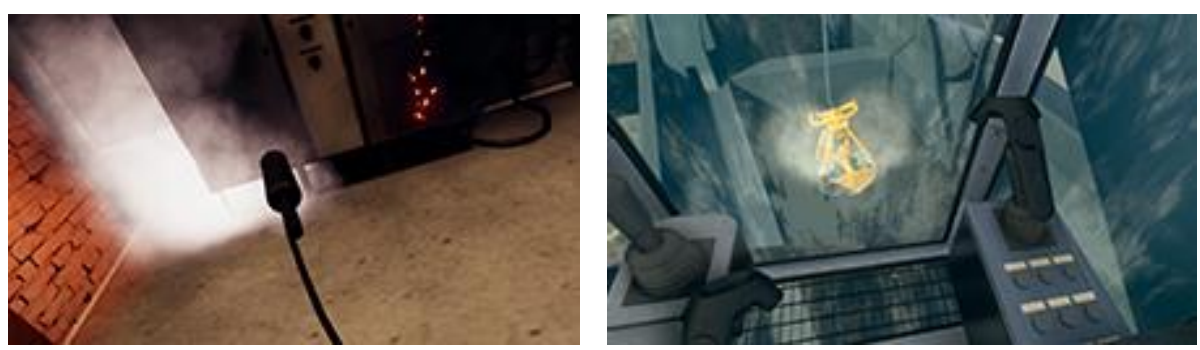

Fig. 2. VR Safety Training solutions from Turku University of Applied Sciences. 


\section{Monetization Geo-socio-techno-economic Influence Factors.}

Besides the type of games and their area of application there are many other external factors that impact monetization strategies and approaches. Socio-geographic and socio-economic influences on how gamers, interact with each other and with the games, influence the game monetization practices selected per case.

Aspects such as the financial status of the player's income can affect the way gamers spend. Surprisingly people who earn more than $£ 90,000$ per year are less likely to spend on game microtransactions despite their financial ability [17]. On the other hand, people with associate degrees or high school diplomas tend to spend most in-game purchases. This difference in income and education highlights a very specific demographic point and the psychological aspect of superiority. It is hypothesized that people with medium income buy more in-game content as it provides them with a feeling of superiority. This need can be correlated with the Maslow's hierarchy of needs as the main aspect people with medium income fail into [18].

Riot Games, the multibillion-dollar company behind "League of Legends" is known to adjust the prices for its digital currency, known as Riot Points, on its online store based on the average wealth of each geographic region and/or the GDP per country [19]. In Europe for example, the smallest amount of money someone can spend is $2.50 €$ (2.2£) for 400 Riot Points while the maximum is $50 €(43.75 £)$ for 9.300 Riot Points. In the USA however the company has different pricing limits where the minimum is $5 \$$ (3.82£) for 650 Riot Points and the maximum is $100 \$(76.4 £)$ for 15.000 Riot Points. Similar to the European pricing limits is also Mexico despite the fact that it is next to the USA. In Mexico, the minimum is amount a gamer can spend is $55 \mathrm{Mex} \$(2.2 £)$ for 555 Riot Points while the maximum is 1.320 Mex\$ (52.8£) for 15.780 Riot Points. Table 2 indicates the pricing differences under one currency, the Great Britain Sterling, and also presents the cost per Riot Point in the minimum and the maximum purchase limits.

Table 2. Riot Points buying value in various geographic regions.

\begin{tabular}{lcclccl}
\hline County & $\begin{array}{l}\text { Minimum } \\
\text { Purchase }\end{array}$ & $\begin{array}{l}\text { Minimum } \\
\text { Riot Points }\end{array}$ & $\begin{array}{l}\text { Cost/Riot } \\
\text { Point in } £\end{array}$ & $\begin{array}{l}\text { Maximum } \\
\text { Purchase }\end{array}$ & $\begin{array}{l}\text { Maximum } \\
\text { Riot Points }\end{array}$ & $\begin{array}{l}\text { Cost/Riot } \\
\text { Point in } £\end{array}$ \\
\hline EUROPE & $2.50 €$ EUR & 400 & 0,0055 & $50 €$ EUR & 9.300 & 0.0047 \\
USA & $5.00 \$$ USD & 650 & 0,0058 & $100 \$$ USD & 15.000 & 0.0050 \\
MEXICO & $55.00 \$$ MXN & 555 & 0,0039 & $1,320 \$$ MXN & 17.780 & 0.0029 \\
\hline
\end{tabular}

Geo-economic factors can also be combined with geo-cultural factors not only in direct game monetization of the game access costs but also on the game devices. In Asia mobile gaming is very common. Asian players either through mobile games or handheld consoles, enjoy playing video games while being outside, during public transportation or in between work or school breaks [20]. The same cannot be said for the western market however. While mobile and handheld gaming still exists in the west, it is not considered a legitimate method of gaming by many people. Game developers must be very careful where and when they release their new projects in order to predict its success more precisely. 
A recent and interesting example of game release which did not go as expected is the way Blizzard entertainment presented their newest mobile game, Diablo Immortal, to the western audience.

Diablo has been a successful series that slowly gained a loyal PC fanbase. Blizzard is a company which has all of its greatest games on PC, and recently on consoles. However, the decision to release the newest Diablo game as a mobile exclusive had a severe impact on Blizzard's profits with its share-value to drop significantly, more than $30 \%$, as indicated in figure 3. [21]

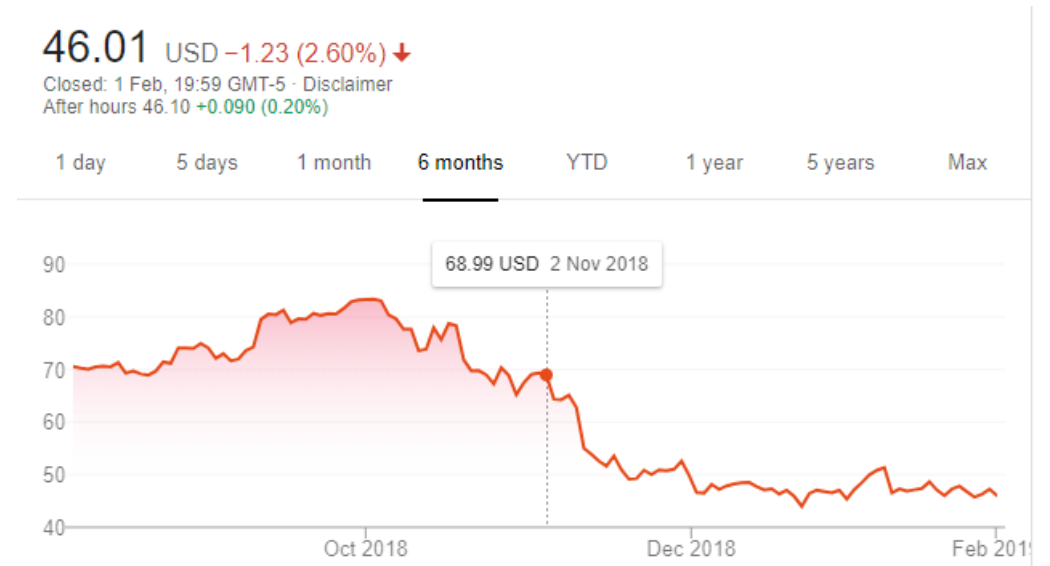

Fig. 3. Blizzard Activision stock after revealing on Nov.2, 2018 the release day of Diablo Immortal on mobile.

\section{Monetization Pre and Post conditions, Addiction and Ethics.}

Selecting the best modernization approach in games of any kind is highly related to the type of game itself and its players target group.

Microtransactions based game monetization is one of the most common method used today by most game developers and the one with the most critical pre and post conditions to apply. Microtransactions are highly related to the player's culture, financial ability to pay the game effectively, geographic locations, social status and much more. They are applied to large target groups in an indirect and discrete way trying not to disrupt the gameplay, the gaming ethics and the gamer's communities. However, microtransactions are not always quite innocent and there can be serious ethical issues on the way they are used as game pre- and post-conditions.

A key requirement to identify the proper monetization strategy is the device games are played on (gaming console, computer, mobile phone, etc). Paywalls for mobile games, subscriptions for PC games and loot-boxes for console games are the most popular monetization practices with different pre-conditions and post conditions but all under the microtransaction strategy.

The most common paywall is the patience paywall were the player is being stopped from progressing further into the game by making the resources or time demanded to progress extremely high or difficult. Players will either spend weeks trying to make it 
past the absurd hurdles set before them or they can simply pay to get over them instantly. Mobile developers deploy multiple paywalls within each game, each spaced apart from the next, in order to profit from impatient players. What makes this method ethical is that technically the game can certainly be finished without paying, but what is "unethical" is that without paying the game can be time consuming and frustrating. For the paywalls to work, the game must "shower" the player with rewards and then slowly give them less until they finally face the wall, creating this way a form of addiction. Once the player gets past the paywall this loop starts again providing the player with an addicting feeling accomplishment.

Subscription is another method of monetization used in many games operating on all devices, but it is mostly used by PC game developers. It is very similar to a paywall but instead of having to pay once to get over it, the players need to pay monthly or yearly in order to maintain their right to progress or even play. Some games offer optional subscriptions that only provide benefits while others make them mandatory. The pre-conditions for a successful subscription system are either stopping the player from progressing until a subscription is bought or letting the player progress slowly but keeping many of the useful and beautiful in-game features away, while constantly promoting them. After the subscription is bought the player feels the need to maintain what they obtained hence being pressured to keep their subscriptions active.

Outside of paywalls and subscriptions, there is another method commonly used in the console gaming industry that rose to popularity in recent years. That method is the loot-boxes and it was popularized recently as a way to make the purchase of game cosmetics more fun and addicting for the players, while profitable for the developers by integrating the sense on gambling. Loot-boxes contain numerous in-game cosmetics that usually dont affect the gameplay. A loot-box always costs the same but the contents within it are random. This is a very common trend when it comes to monetization methods as it creates a form of addiction. One of the oldest forms of addiction is gambling, and that is what loot boxes capitalize on. Gamer's hopes that the next loot-box they get will possibly have what they want is what keeps them purchasing more. A precondition for loot-boxes to sell is to offer items worth the gamble. A simple way of making somethings value inflate is by keeping them rare. Rare items are desired so much that in some cases these items are sold in community markets between players for incredible amounts of money [22].

Gaming monetization is a very serious part of any game development project. Game ethics on the other hand are closely related to the monetization strategy and practices adopted by the game designers. What is legal might not always be ethical, but since it is legal it can be considered ethical and this is where monetization pre- and post-conditions and shall be further developed with more attention to the game and the gamers.

\section{$9 \quad$ Areas of Further Research.}

Identifying monetization techniques and aligning them with various gamification domains is the first step towards understanding gamification economics. This paper presented an overview of the monetization concept and introduced specific methods, practices, precondition and post conditions towards monetizing a gamified application. 
However, the concept of gamification monetization extends furthermore in a micro and macro analysis, decision, strategy and ethics.

The implementation cost of a gamified application impacts significantly the monetization approach that will follow. The return on investment on gamification projects is vital to the developers due to the high cost of the technology involved, and the short life span of operations, since players/clients demand continuous updates and alignment with the gaming trends. On the other hand, the high cost of gaming projects shall not be passed only on the players / clients and monetization practices shall involve more game sponsorships, and this is an area this research will extend.

Solving this equation of how cost distribution is spread on various revenue streams is more of a strategy than a financial challenge. This research will also extend towards a further and more in-depth analysis of the monetization strategy gamified applications and projects could adopt. Future work will target the development of a monetization strategy generator which will compose the right monetization approach per activity type within the game specifications and operations.

\section{Conclusions.}

Gamification and monetization are two closely related concepts with a distant background. The creative dimension of gamification has to be aligned with the practical dimension of monetization.

Creative arts and economics cannot be aligned effectivity all the times as the cost of creativity might not be covered effectively with the monetization practices of the gamified project. After all, art can be expensive. However, the growth of the games industry and the high volumes of funds being involved, together with the tremendous revenues generated, allows many monetization practices to be considered valid, effective and ethical. On the other hand, the increase of the competition in the gaming industry and the increase of the type of gamified applications will request more specific and more ethical monetization strategies and methods in the very near future. This is something this research has indicated and approached with the geographical, social, technical, economical and other influence game factors that can determine the pre-conditions and the post-conditions of the monetization practices to be selected.

The paper approached this mapping process and resented the base for understanding the monetization challenge in gamification per type of game and game device. Further research will be conducted to extend this work on more advanced areas where gamification monetization can be modelled under a structured methodology and framework.

\section{References}

1. ESA: Essential Facts About the Computer and Video Game Industry, $\mathrm{http}: / /$ www.theesa.com/wp-content/uploads/2014/10/ESA_EF_2014.pdf

2. Statista: Video Game Industry - Statistics \& Facts, https://www.statista.com/topics/868/videogames/

3. The Association of UK interactive entertainment: The games industry in numbers, https://ukie.org.uk/research 
4. Salen K. and Zimmerman E.: Rules of play: Game design fundamentals. MIT Press, Cambridge, MA, (2004)

5. Kiryakova G., Angelova A., and Yordanova L.: Gamification in Education, https://www.sun.ac.za/english/learning-teaching/ctl/Documents/Gamification\%20in\%20education.pdf

6. Lundgren S. and Björk S.: Game mechanics: describing computer-augmented games in terms of interaction. In: Proceedings of TIDSE (2003)

7. Hays, R. T.: The effectiveness of instructional games: A literature review and discussion. Technical Report. Naval Air Warfare Center Training Systems Division. Florida. (2005).

8. Business Insider. "Gamification" Techniques Increase Your Employees' Ability To Learn By 40\%. http://whttp://www.businessinsider.com/gamification-techniques-increase-your-employees-ability-to-learn-by-40-2013-9

9. Caponetto I., Jeffrey Earp J. and Ott M.: Gamification and Education: A Literature Review. http://www.itd.cnr.it/download/gamificationECGBL2014.pdf

10. Dicheva, D., Dichev, C., Agre, G. and Angelova, G.: Gamification in Education: A Systematic Mapping Study. International Forum of Educational Technology and Society. 18, 75--88 (2015).

11. Lameras P., Arnab S., Dunwell I, et al.: Essential features of serious games design in higher education: linking learning attributes to game mechanics. In: Br J Educ Technol (2017)

12. Inverse.This is How Facebook Actually Makes All Its Money, https://www.inverse.com/article/44566-how-does-facebook-make-money-mark-zuckerberg

13. Liu, C.Z. et al.: Effects of Freemium Strategy in the Mobile App Market: An Empirical Study of Google Play. Journal of Management Information Systems. 31, 3, 326--354 (2014).

14. Newszoo. Top Public Video Game Companies | By Revenue : https://newzoo.com/insights/rankings/top-25-companies-game-revenues/

15. Recode. Fortnite is generating more revenue than any other free game ever. https://www.recode.net/2018/6/26/17502072/fortnite-revenue-game-growth-318-million

16. Luimula, M., Ailio, P., Ravyse, C., Katajapuu, N., Korpelainen, R., Heinonen, A., and Jamsa, T.: Gaming for Health Across Various Areas of Life, In: 9th IEEE International Conference on Cognitive Info-communications CogInfoCom 2018, pp. 247--252. (2018)

17. Priceonomics: Gender, Income \& Education: Who Plays Video Games?. Priceonomics Data Studio https://priceonomics.com/gender-income-and-education-who-plays-video-games/

18. Taormina R. J., and Gao J. H.: Maslow and the Motivation Hierarchy: Measuring Satisfaction of the Needs. The American Journal of Psychology 126: 155. University of Illinois Press. (2013)

19. The league of legends on line store: https://na.leagueoflegends.com/en/

Mashable. A little over half of the world's mobile game revenue comes from Asia. Nov. 17, 2015.https://mashable.com/2015/11/17/mobile-game-revenue-asia/?europe $=$ true\#snOPqkWS6uq7.

20.NASDAQ:ATVI,https://www.google.com/search?q=NASDAQ:ATVI\&tbm=fin\#scso=_Wx DhW5LmHoKz9QOT14fwCQ2:0, CYNUXKu6AviU1fAP 6Ws4AI2:0

21. Polygon, https://www.polygon.com/2018/1/30/16952248/counter-strike-global-offensivedragon-lore-skadoodle-skin-sale-opskins 